\title{
Processos expansivos da cavidade nasal: avaliação por tomografia computadorizada
}

\author{
Expansile lesions of nasal cavity: assessment by computed tomography
}

\section{Resumo}

Foram analisados, neste trabalho, os aspectos clínicos e tomográficos de 20 pacientes portadores de lesão expansiva com centro na cavidade nasal, sem tratamento cirúrgico prévio. A maioria das lesões (19 casos) teve confirmação histopatológica por biópsia ou excisão cirúrgica, e em apenas um caso (rinolito), o diagnóstico foi estabelecido pela história clínica, exame endoscópico e radiológico. A casuística consistiu de 18 tumores malignos, sendo seis carcinomas ( $\mathrm{C}$ a) epidermóides, três melanomas, dois $\mathrm{C}$ a adenóides císticos, um adenocarcinoma polimórfico de baixo grau, um $\mathrm{Ca}$ indiferenciado, um $\mathrm{C}$ a neuroendócrino, um linfoma não-H odgkin, um rabdomiossarcoma alveolar, um sarcoma fusocelular grau II e um estesioneuroblastoma. A penas dois casos eram histologicamente benignos: um hemangioma capilar lobular e um rinolito. As principais manifestações clínicas foram obstrução nasal e epistaxe (70\%), comumente associadas à sinusite (85\%). Q uanto à localização, foi mais freqüente à esquerda (55\%) e no andar médio da cavidade nasal (90\%). A maioria das lesões (60\%) mostrou grande volume ao diagnóstico inicial e realce pelo meio de contraste semelhante à musculatura mastigatória. $0 \mathrm{~s}$ Ca epidermóides apresentaram padrão de destruição relacionado ao volume. 0 achado tomográfico mais freqüente foi massa de partes moles com erosão óssea adjacente, todos de natureza maligna. $N$ este grupo houve erosão do septo nasal em $65 \%$ dos casos e invasão das estruturas vizinhas à cavidade nasal em $70 \%$, principalmente das células aéreas etmoidais. Calcificação esteve presente somente no estesioneuroblastoma. A tomografia computadorizada mostrou melhor compreensão da anatomia da face, indispensável à adequada avaliação das lesões quanto às suas características e extensão, bem como no planejamento do acesso cirúrgico e do campo a ser irradiado.

Dissertação de mestrado apresentada à UFRJ em 2004.

Endereço para correspondência: V.F.M . Clínica Radiológica Esplanada - CEP: 29702-120 - Colatina, ES - Brasil. Tel: (27)3722-4048.

E-mail: vfmendonca@ig.com.br 